bypass reduces oxidative myocardial damage and nitric oxide during cardiac operations in the adults. J Thorac Cardiovasc Surg 1998:116:327-34.

2. Wachtfogel YT, Kucich U, Greenplate J, et al. Human neutrophil degranulation during extracorporeal circulation. Blood 1987;69: 324-30.

3. Butler J, Pillai R, Rocker GM, Westaby S, Parker D, Shale DJ. Effect of cardiopulmonary bypass on systemic release of neutrophil elastase and tumor necrosis factor. $\mathbf{J}$ Thorac Cardiovasc Surg 1993;105:25-30.

4. Gu YJ, van Oeveren W, Akkerman C, Huyzen RJ, Boonstra PW, Wildevuur CRH. Heparin-coated circuits reduce the inflammatory response to cardiopulmonary bypass. Ann Thorac Surg 1993; 55:917-22.

5. Korn RL, Fisher CA, Livingston ER, et al. The effect of Carmeda Bioactive Surface on human blood components during simulated extracorporeal circulation. J Thorac Cardiovasc Surg 1996;111: 1073-84.

$12 / 8 / 96853$

\section{Reply to the Editor}

We thank Dr Gu and his colleagues for their interest in our recent article. ${ }^{1}$ They describe a prospective study in 60 patients in whom cardiopulmonary bypass (CPB) was used, but did not mention where these results have been published. They did not find a correlation between $\mathrm{PO}_{2}$ on CPB and neutrophil elastase release. However, there are several methodologic differences between our two studies. First, they wrote, "a large variation in $\mathrm{PO}_{2}$ appeared during perfusion," and their results showed that $\mathrm{Po}_{2}$ varied between 107 and $440 \mathrm{~mm} \mathrm{Hg}$ at the start of cooling, between 80 and $308 \mathrm{~mm} \mathrm{Hg}$ during hypothermia, and between 128 and $317 \mathrm{~mm} \mathrm{Hg}$ on average during CPB. It is not clear whether these disparities in $\mathrm{PO}_{2}$ occurred randomly and within the same patient. Further, it is not evident whether normoxia was maintained at all times, as it was done in our study. This seems very important, because we also did not find a positive correlation between $\mathrm{Po}_{2}$ and elastase at the beginning of CPB with low elastase levels, but when $\mathrm{PO}_{2}$ was controlled to normoxic levels during the whole period of extracorporeal circulation, elastase release was reduced significantly compared with high levels after persistent hyperoxia. Second, they measured $\mathrm{PO}_{2}$ levels only 5 times during $\mathrm{CPB}$ : $\mathrm{Po}_{2}$ between these measurements is unknown and might have reached undesired levels. In our study, on-line $\mathrm{PO}_{2}$ measurements were applied and the $\mathrm{PO}_{2}$ during CPB was controlled at all times. Third, different types of oxygenators were used during their study. These differences might have influenced results, as our data (unpublished) indicate, namely, that elastase release varies between oxygenators. Fourth, blood samples in their study were obtained from the radial artery, whereas our blood samples were taken from coronary sinus blood and from the venous side of the CPB circuit. The significance of this detail, and whether this might have influenced results, however, remains unknown.

The authors mention that "elastase release during CPB has been known to be largely attributed to blood interaction with the artificial surface of the extracorporeal circuit."2,3 These results confirm (as mentioned above) our own findings, in which membrane oxygenators cause less oxidative damage than bubble oxygenators. In their explanation, the authors reason: "It could well be that normoxic CPB had reduced the cardiac source of elastase but that the effect had been systematically counteracted by other factors, such as bloodmaterial interaction." This statement is in contrast to our findings, in which values from coronary sinus blood and systemic circulation were not different and improved after normoxia. Independently from reduced leukocyte elastase levels, there are additional benefits from normoxic CPB. ${ }^{4.5}$

In summary, there are considerable methodologic differences between their study and ours. Our protocol of controlled normoxic CPB for the first time establishes a correlation between $\mathrm{PO}_{2}$ and leukocyte elastase, whereas their investigation of "a large variation in $\mathrm{Po}_{2}$ " could not confirm this finding. I do agree with their conclusion that further studies are necessary to address this issue. Furthermore, the clinical significance of reduced leukocyte elastase after normoxic CPB has to be established.

Kai Ihnken, $M D$

Department of Surgery Stanford University Hospital

Room $\mathrm{H3680}$

300 Pasteur Dr

Stanford, CA 94305

\section{REFERENCES}

1. Ihnken K, Winkler A, Schlensak C, et al. Normoxic cardiopulmonary bypass reduces oxidative myocardial damage and nitric oxide during cardiac operations in the adult. J Thorac Cardiovasc Surg 1998;116:327-34.

2. Wachtfogel YT, Kucich U, Greenplate J, et al. Human neutrophil degranulation during extracorporeal circulation. Blood 1987;69: 324-30.

3. Butler J, Pillai R, Rocker GM, Westaby S, Parker D, Shale DJ. Effect of cardiopulmonary bypass on systemic release of neutrophil elastase and tumor necrosis factor. J Thorac Cardiovasc Surg 1993;105:25-30.

4. Ihnken K, Morita K, Buckberg GD, Sherman MP, Ignarro LJ, Young HH. Studies of hypoxemic oxygenation injury: with aortic clamping. XIII. Interaction between oxygen tension and cardioplegic composition in limiting nitric oxide production and oxidant damage. J Thorac Cardiovasc Surg 1995;110:1274-86.

5. Morita K, Ihnken K, Buckberg GD, Sherman MP, Young HH. Studies of hypoxemic oxygenation injury: Without aortic clamping. IX. Importance of avoiding perioperative hyperoxemıa in the setting of previous cyanosis. J Thorac Cardiovasc Surg 1995;110: 1235-44.

$12 / 8 / 96852$

\section{The extracardiac Fontan procedure using a pedicled pericardial roll without cardiopulmonary bypass}

\section{To the Editor:}

We congratulate Okabe and his colleagues for their successful establishment of total cavopulmonary connection using a pedicled autologous pericardial roll without the aid of cardiopulmonary bypass. ${ }^{1} \mathrm{We}^{2}$ used similar surgical maneu- 